\title{
Modelo de Desenvolvimento de Objetos de
}

\section{Aprendizagem Baseado em Metodologias Ágeis e}

\section{Scaffoldings}

Fábio Lapolli

UFRJ / NCE - Av. Brigadeiro Trompowski, s/n - Cidade Universitária - 20.001-970 - Rio de Janeiro - RJ- Brasil lapollimaster@gmail.com

Cláudia L. R. Motta

UFRJ / NCE - Av. Brigadeiro Trompowski, s/n - Cidade Universitária - 20.001-970 - Rio de Janeiro - RJ- Brasil claudiam@nce.ufrj.br

\author{
Cristiane Moura Cruz \\ UFRJ / NCE - Av. Brigadeiro Trompowski, s/n - Cidade \\ Universitária - 20.001-970 - Rio de Janeiro - RJ- Brasil \\ crismouracruz@hotmail.com
}

Carlo E. T. Oliveira

UFRJ / NCE - Av. Brigadeiro Trompowski, s/n - Cidade Universitária - 20.001-970 - Rio de Janeiro - RJ- Brasil cetoli@nce.ufrj.br

\begin{abstract}
Resumo O desenvolvimento de objetos de aprendizagem exige modelos instrucionais e de desenvolvimento flexíveis, por se tratar de uma categoria de software com um conjunto de requisitos bastante específicos e demandas tecnológicas singulares. $O$ uso de metodologias ágeis para o desenvolvimento de objetos de aprendizagem pode facilitar esse processo permitindo a modelagem das funcionalidades baseados nos requisitos de comportamento do aluno. O presente artigo tem como objetivo discorrer sobre uma experiência no de desenvolvimento de objetos de aprendizagem, baseado em metodologias ágeis e interface baseada em scaffoldings.
\end{abstract}

Palavras-Chave: Objetos de Aprendizagem, Metodologias Ágeis, Scaffolding, Desenvolvimento Dirigido ao Comportamento

\begin{abstract}
The development of learning objects requires instructional models of flexible development, because it is a software category with a group of specific requisites and singular technological demands. The agile methodology use for learning object development may facilitate this permitting the functionality based on the student's behavior requisites. The present article has the objective to describe the experiment the learning object development based on agile methodologies and interface based on scaffoldings.
\end{abstract}




\section{Introdução}

As instituições de ensino investem em seus recursos humanos visando produtividade, eficiência e qualidade na produção de material didático digital diferenciado, para isso, é imprescindível a escolha de uma metodologia mais adequada ao processo de desenvolvimento que atenda às necessidades organizacionais e pedagógicas de forma prática. A abordagem de desenvolvimento tradicional já não satisfaz as necessidades das propostas educacionais atuais, principalmente as de domínio complexo, pois nem sempre contribuem para a aprendizagem final. Portanto, é preciso pesquisar abordagens de desenvolvimento de recursos educacionais mais adequados a prática pedagógica.

Nos últimos anos o uso de objetos de aprendizagem (OA) se tornou freqüente na prática pedagógica, entretanto, percebemos que o atual modelo instrucional e de desenvolvimento tem generalizado as características fundamentais desse recurso devido ao alto custo de produção e o vasto conteúdo educacional, o que inviabiliza a adequação das funcionalidades do OA as necessidades específicas de cada curso. No desenvolvimento de um objeto de aprendizagem para processo de ensino e aprendizagem da disciplina Fundamentos da Meteorologia, pudemos perceber a necessidade de inovação no modelo de projeto instrucional e de desenvolvimento. Motivados também pela expansão e uso das técnicas de desenvolvimento ágil de software e conceitos de interface homemcomputador (IHC), verificamos que a aplicação de suas práticas poderia incorporar melhorias no projeto instrucional e, conseqüentemente, na produção de recursos didáticos.

A proposta deste trabalho aborda a adaptação do Behaviour-Driven Development (BDD) e um modelo de design de interação apoiado por scaffoldings como uma das atividades de um projeto instrucional e de desenvolvimento, possibilitando a identificação dos cenários que permitam ao aluno interiorizar o conceito de tal forma que seja possível a sua abstração e aplicação em diferentes situações, inclusive as não previstas durante o seu treinamento. $O$ artigo está organizado em cinco seções. Nas seções 2 e 3 apresentamos desenvolvimento orientado ao comportamento e modelo de proposta instrucional baseado em BDD e desenvolvimento ágil em objetos de aprendizagem. Na seção 4 o modelo de projeto de interface apoiado por scaffoldings. Na seção 5 apresentamos a metodologia de avaliação e por fim apresentamos as considerações finais desta proposta.

\section{Desenvolvimento Orientado ao Comportamento}

Test-Driven Development (TDD) foi uma metodologia ágil de desenvolvimento de software introduzida por Kent Beck [2,3] para produzir o que se chama de "código limpo que funciona". Apesar de ser um processo simples, alguns desenvolvedores têm dificuldades de aplicar essa técnica no dia-a-dia e não conseguem guiar um projeto orientado a objetos a partir de testes. No TDD os testes são escritos antes do código de produção, compilação e verificação de falhas, provendo o que é preciso para escrever um código de produção que satisfaça esses testes. O ciclo básico do TDD é formado pelas seguintes etapas:

- Desenhe o que você quer que seu código faça;

- Escreva o teste;

- Execute o teste, provocando a falha;

- Refatore o código para passar no teste;

- Reinicie o ciclo.

Segundo Dave Astels [1], a grande vantagem dessa prática não está nos testes gerados, mas sim no fato de se pensar no design antes de escrever a primeira linha de código, no momento em que se descreve o comportamento do sistema. Assim nasceu outra metodologia ágil, sendo o desenvolvimento orientado a comportamento (BDD, do inglês Behaviour-Driven Development), que com o tempo evoluiu para um processo que engloba desde a análise de requisitos, até o desenvolvimento do código. $\mathrm{O}$ desenvolvimento orientado a comportamento é semelhante ao TDD em vários aspectos, mas embora as diferenças pareçam sutis influenciam grandemente no modo de criar um sistema. O BDD transfere o foco dos testes de implementação para os comportamentos que o sistema expõe. Uma vantagem da abordagem BDD é que os comportamentos se modificam menos vezes do que os testes e, tipicamente, tais modificações refletem a necessidade de novas funcionalidades do sistema. Os comportamentos do sistema também podem ser descritos em vários níveis de granularidade. Por exemplo, podemos falar sobre os comportamentos que o sistema deve apresentar no conjunto ou caracterizar comportamentos que caracterizam componentes individuais do sistema.

O BDD apresenta um framework baseado em três princípios:

- A área de negócios e a de tecnologia precisam se referir a mesma parte do sistema da mesma forma; 
- Toda parte do sistema precisa ter um valor identificável e verificável para o negócio;

- Analisar, projetar e planejar tudo de cima a baixo tem retorno decrescente.

Podemos definir o BDD como a união de várias práticas consideradas ágeis e úteis no desenvolvimento de software, cuja ênfase está nas funcionalidades de alto valor e na redução dos custos de mudança por meio da identificação do que de fato está sendo testado.

\subsection{História do Usuário}

Para Boyle et. al [4], projetos de desenvolvimento de objetos de aprendizagem começam, com uma análise das necessidades do aluno. O resultado desta análise serve de base para o design e o processo de desenvolvimento. Cohn [6] afirma que a história de um usuário escrita por ele, descreve o que é valioso para os interessados de um sistema ou software e traz em si três características:

1. Descrição escrita da história, usada para planejamento e como lembrete;

2. Conversações sobre a história que servem para aprofundar os detalhes;

3. Testes e documentos que transmitem informações que podem ser utilizados para determinar quando uma história está completa.

Usando o acrônimo em inglês INVEST, Cohn [6] diz que uma boa história do usuário é: Independente; Negóciável; Valiosa ao comprador; Estimável; Small (pequena); Testável. Na escrita da história do usuário utilizamos o seguinte modelo:

Como um [pessoa ou papel desempenhado]

Eu quero [funcionalidade]

Para que [benefício ou valor dessa funcionalidade ao negócio] como um controlador de tráfego aéreo

eu quero Obter informações meteorológicas e climáticas

para utilizer estas informações em outras atividades do sistema

Figura 1 - Exemplo de Story Card

Uma vantagem significativa de story cards é que como são freqüentemente escritas utilizando artefatos muito simples, como por exemplo, fichas, a identificação de novas histórias de usuário ou particionamento de histórias já existentes ou, ainda, a retirada de histórias que não são mais consideradas parte do escopo é uma atividade de processo considerada relativamente fácil. Essas histórias podem ser usadas para descrever uma grande variedade de requerimentos. Embora o nome histórias do usuário seja semelhante a "casos de uso", as histórias do usuário não são simplesmente uma versão reduzida de um caso de uso, elas são de fato um tipo diferente de artefato de desenvolvimento. No cartão definimos também os critérios para a sua aceitação (Acceptance Criterias). Uma história do usuário só estará pronta quando todos os seus critérios de aceitação forem atendidos. David Churchville [5] apresenta algumas dicas para escrever boas histórias do usuário. Elas devem: i) estar focadas naquele que necessita da solução; ii) ser perfeitamente explicáveis em 30 segundos; iii) "caber" no trabalho a ser executado em uma semana pela equipe de desenvolvimento e iv) ser facilmente testáveis.

\subsection{Critérios de Aceitação}

O comportamento de um sistema constitui o seu critério de aceitação. Isto é, se o sistema cumpre todos os critérios de aceitação assumimos que ele se comporta corretamente. Caso contrário, não. Assim, Dan North [12,13] aponta que um padrão para os critérios de aceitação da história do usuário é bastante livre, a fim de não ser artificial para os analistas, mas suficientemente estruturado de modo a permitir a divisão da história nos fragmentos que a compõem e automatizá-los. Os critérios de aceitação de cenários, tomaram a seguinte forma: Dado algum contexto inicial (os dados), Quando ocorre um evento, então assegure alguns resultados.

Em dado definimos tudo o que precisamos antes para quando o evento ocorrer então verificarmos o resultado. Note que uma funcionalidade pode admitir $\mathrm{N}$-cenários. 


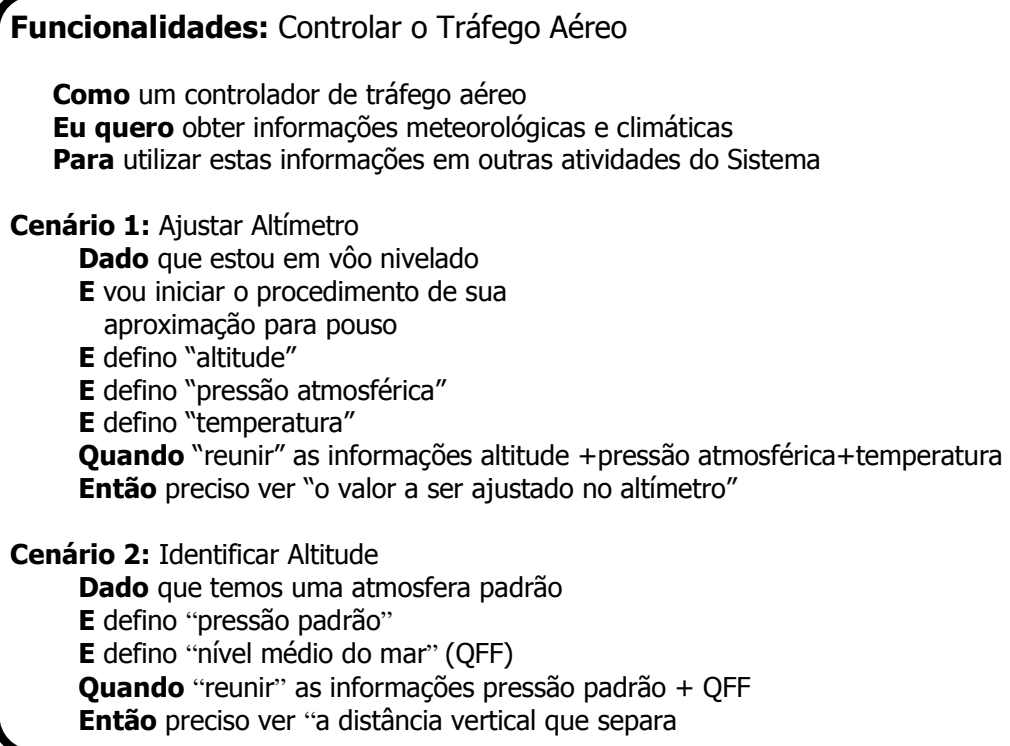

Figura 2 - Exemplo de história de usuário

O uso deste padrão fornece uma linguagem de fácil entendimento para a área de negócios e a de tecnologia, possibilitando a escrita de melhores softwares em que o foco está na essência, no que realmente importa.

\section{Modelo de Projeto Instrucional Baseado em BDD}

O modelo proposto foi idealizado levando em consideração os pressupostos de boas práticas das metodologias ágeis de desenvolvimento, mais especificamente o desenvolvimento dirigido pelo comporta- mento esperado do sistema, que visa aplicar testes unitários, funcionais e de integração para descrever como uma determinada funcionalidade deveria trabalhar. Sendo assim, o modelo foi baseado no padrão de teste de aceitação definido por Dan North [12, 13] visando atender algumas expectativas e necessidades apontadas por instrutores e alunos durante as entrevistas semi-estruturadas. Assim definimos em [10] o Modelo de Projeto Instrucional Dirigido pelo Comportamento, composto por cinco etapas: (1) Programa Oficial da Disciplina; (2) Proposta de Atividades; (3) Plano de Atividades; (4) Formas de Mediação; (5) Análise do Processo e do Produto.

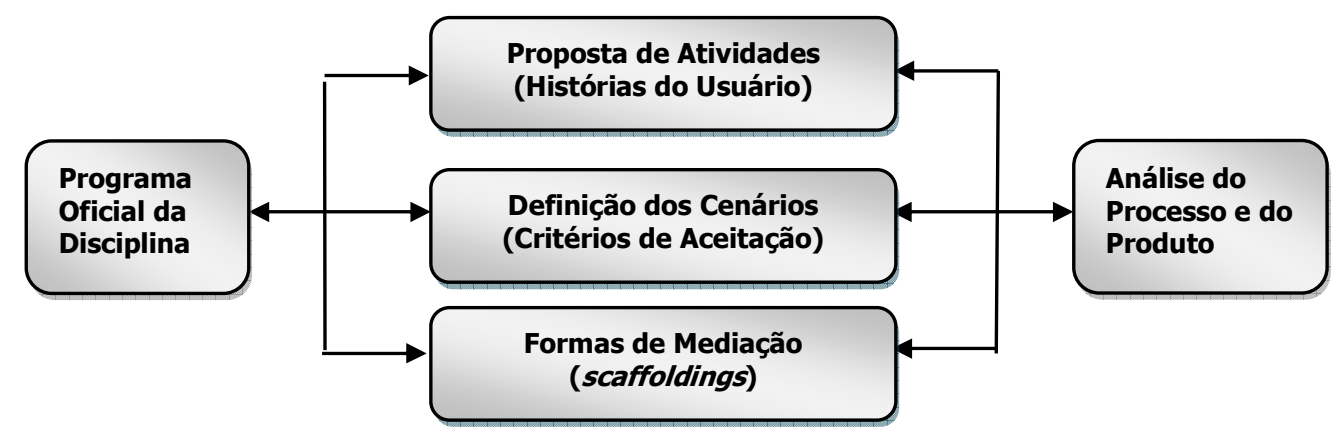

Figura 3 - Modelo de projeto instrucional dirigido pelo comportamento

\section{$1^{\text {a }}$ Etapa: Programa Oficial da Disciplina}

Nesta etapa a equipe responsável pela área de Treinamento e Desenvolvimento deve identificar os conteúdos (conhecimentos/habilidades) que permitirão alcançar os objetivos (resultados) esperados. A esta combinação chamamos de Programa Oficial da Disciplina. Cursos que visam preparar profissionais para atuar em Sistemas Complexos contêm no seu pro- 
grama oficial, diversas disciplinas distribuídas por vários grupos disciplinares. Cada disciplina ocupa um lugar próprio na formação básica destes profissionais, porém o programa oficial deve favorecer a aquisição simultânea de saberes oriundos de diferentes áreas dado sua característica multidisciplinar e interdisciplinar. O produto desta etapa é, portanto, um Programa não linear (em alguns momentos) que possibilite diferentes percursos de aprendizagem, com vistas a potencializar os resultados a partir do perfil de cada grupo de profissionais.

\section{$2^{\text {a }}$ Etapa: Proposta de Atividades}

Da proposta de atividades de treinamento e desenvolvimento dos profissionais que irão atuar em Sistemas Complexos importa salientar que ela precisa atender aos conhecimentos, habilidades e comportamentos desejados para a realização de procedimentos operacionais previstos em sua rotina de trabalho.

Durante esta etapa são definidos os objetivos de aprendizagem específicos para cada assunto; os conteúdos que serão desenvolvidos; e as atividades de aprendizagem. Cabe salientar que as atividades de aprendizagem devem estar fundamentadas nas teorias de aprendizagem adequadas tanto para o ensino do conteúdo quanto para as habilidades e comportamentos a serem desenvolvidos.

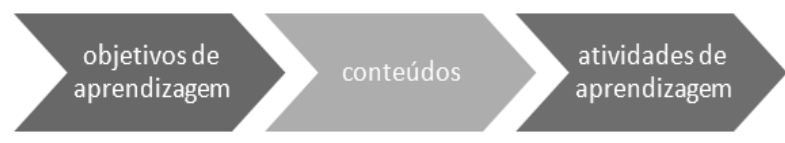

Figura 4 - Produtos da etapa proposta de atividades

Elaborada a proposta de atividades, podemos iniciar a etapa de identificação dos cenários que serão utilizados para contextualizar os conhecimentos necessários para a realização das tarefas, apresentada a seguir.

\section{$3^{\text {a }}$ Etapa: Definição dos Cenários}

Segundo definição do dicionário Aurélio, cenário é o lugar onde decorre uma ação ou parte da ação de uma peça, romance, filme etc. Sob o ponto de vista educacional, cenários são representações realistas (simulações) com a finalidade de prover a experimentação e exploração de fenômenos (hands-on). Nesta etapa são recomendadas algumas atividades da análise do trabalho cognitivo como, por exemplo, entrevistas com expertises e observação in loco. Existem diferentes métodos e ferramentas para realizar a análise do trabalho cognitivo. Para que atenda a expectativa de construção de cenários educacionais, os métodos e ferramentas utilizados na identificação e definição de cenários devem incluir o mapeamento das tarefas, identificando e priorizando os pontos de decisão crítica.A Figura 5mostra os produtos desta etapa. Eles são bastante úteis para explicitar como um conceito deve ser apresentado, de maneira tal que facilite a compreensão de sua aplicação prática.

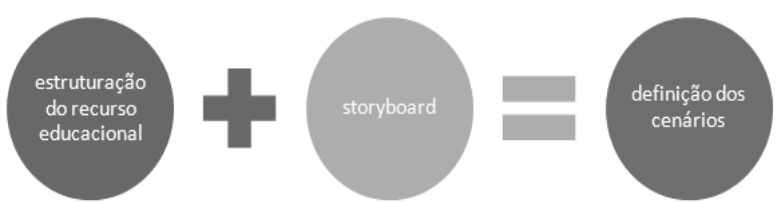

Figura 5 - Produtos da etapa definição dos cenários

Estes produtos são de extrema importância para a escolha das formas de mediação e o ponto de partida para suas respectivas construções.

\section{$4^{\text {a }}$ Etapa: Formas de Mediação}

Dentre as ações delineadas no modelo de projeto instrucional dirigido pelo comportamento, conta a escolha e construção das formas de mediação que serão utilizadas para apoiar e/ou facilitar a aprendizagem dos que almejam uma formação profissional com mais eficiência, eficácia e agilidade. Assim, nesta etapa, a equipe de Treinamento e Desenvolvimento especifica e cria os recursos educacionais adequados para facilitar o ensino e aprendizagem de profissionais para atuar em Sistemas Complexos. De modo semelhante à etapa Proposta de Atividades, uma mesma storyboard pode dar origem a diferentes recursos educacionais. Além disso, o modelo possibilita combinar diferentes teorias de aprendizagem em uma mesma forma de mediação.

\section{Etapa: Análise do Processo e do Produto}

Embora o termo análise seja freqüentemente utilizado para designar a fase inicial de um processo, no modelo de projeto instrucional dirigido pelo comportamento ele representa nossa constante busca pelos interesses e aspectos relevantes a serem considerados na formulação e construção de um curso de formação profissional. Nesta etapa, quanto mais precisas forem as informações coletadas sobre o funcionamento do Sistema e o comportamento esperado para os profissionais que nele atuam, maiores são as possibilidades de planejar de forma mais plena e consciente a disponibilização da disciplina, o que ela pode oferecer e as estratégias mais eficazes para facilitar a aprendizagem. Uma das vantagens do modelo proposto é permitir a análise recursiva do processo e do produto permitindo incorporar melhorias ao longo do processo, o que viabiliza um processo de educação flexível, através de diferentes recursos que despertem no aluno o interesse pelo seu auto desenvolvimento. 


\section{Modelo de Projeto de Inteface}

A incorporação de tecnologias como recurso educacional tem sido incentivada pelo poder de distribuição do conhecimento e pela possibilidade de criar ambientes onde a problematização, a atividade reflexiva, a atitude crítica, a capacidade decisória e a autonomia sejam privilegiadas. Dentre elas destacamos os Objetos de Aprendizagem (OA) por permitir ao aluno perceber onde o conteúdo instrucional se aplica em seu contexto real.

A utilização de cenários em OAs é o meio de representar cenários é um meio de representar, analisar e planejar como um sistema computacional pode causar impacto nas atividades e experiências do usuário. Um cenário é uma descrição em geral narrativa, baseado nas estórias dos usuários, mas também em outros formatos, que as pessoas fazem e experimentam conforme imaginam ou tentam fazer durante o processo operacional de sistemas complexos.

O cenário identifica o usuário como tendo certas motivações para o uso do sistema, descrevendo as ações, tomadas de decisões e razões para essas ações. Para o design de interação, ajuda a visualizar aspectos da atividade e experiência adquirida ou necessária de um usuário.

Durante a fase de análise de requisitos a equipe de desenvolvimento e os usuários negociam abertamente e de forma clara utilizando os cenários e descrições do domínio de uso do sistema. Descrições de cenários hipotéticos facilitam na descoberta das necessidades do usuário que não são óbvias ou aparentes para eles próprios.

Cenários podem ser a unidade de análise para o desenvolvimento de interfaces, explicando as decisões de design através de cenários particulares de interação do usuário e da análise de cenários alternativos.

$\mathrm{Na}$ fase de desenvolvimento propriamente dita, cenários podem ser analisados para identificar os objetos centrais do domínio do problema e articular o estado, comportamento e interação funcional dos objetos de interface.

$\mathrm{Na}$ fase de avaliação, cenários podem ser usados para coletar informações detalhadas sobre como os usuários percebem os conceitos veiculados pela interface. Designs de interface podem ser apresentados a usuários potenciais que tentam explicar o que pensam ser possível fazer e os efeitos esperados de suas ações.
Mesmo na fase de implementação o uso de cenários apresenta benefícios, uma vez que ajuda a manter a equipe de desenvolvimento determinada e desenvolver funcionalidades que de forneçam suporte às atividades dos usuários.

Cenários são a língua franca da ação e experiência do usuário final. A proposta de utilização de cenários pressupõe a visão de sistemas computacionais como transformadores das tarefas do usuário e de suas práticas sociais. Estórias são elementos coesivos importantes em qualquer sistema social; os cenários que a equipe compartilha motivam e direcionam a construção do grupo.

Representam, ainda, uma busca pelo equilíbrio entre intuição criativa e análise, entre a flexibilidade e a informalidade, necessários para a evolução sistemática em direção a um sistema usável.

A partir do levantamento dos requisitos e da definição do modelo de projeto instrucional baseado no comportamento, para que haja o desenvolvimento do OA é necessária a tradução dos conceitos que foram transformados em cenários. Para tal propósito, o modelo de projeto de interface que exerça o papel de mediador entre aluno e conhecimento, poderia facilitar a aprendizagem dos conceitos veiculados na interface não se tratando apenas de aprender a fazer algo, mas de aprender para aprender algum conceito. Assim, o processo de design de interface (design gráfico e de interação) distingue-se em função dos usuários finais ou aprendizes para os quais foram projetados.

A aprendizagem de conceitos através do uso de uma interface educativa está relacionada à construção e simulação de objetos, que são representantes de conceitos abstratos. Tal representação é construída para proporcionar ao usuário a investigação, o levantamento de hipóteses e testes de sua aplicabilidadeda, para que seja conduzido à revisão de suas idéias iniciais e construa seu conhecimento com autonomia. Portanto, numa interface educativa o erro é uma oportunidade para a reconstrução do conhecimento .

Os conceitos numa interface educativa são representados metaforicamente e submetidos às ações dos usuários por meio de um estilo de interação que influencia no potencial da interface para a aprendizagem de conceitos. Em geral, nestas interfaces o aprendiz se vê diante de situações que poderiam envolver a resolução de problemas influenciada pelo estilo de interação adotado, o qual de algum modo deve requerer o uso de recursos mentais. 
Nesse estudo, buscamos através do estilo de interação do usuário com a interface, criar situações promotoras de sentido, fazendo o aluno refletir sobre os conceitos veiculados e sobre a tarefa em execução.

\subsection{Estilos de Interação}

O Estilo de Interação é um termo genérico que inclui todas as formas como os usuários se comunicam ou interagem com sistemas computacionais. Sendo assim, "a interação é um processo que engloba as ações do usuário sobre a interface.

Através de estilos de interação, a correção dos erros através do input de ações corretivas são feitas pelo usuário. Assim, as restrições e correções de erro conduziriam o usuário à reflexão da tarefa em execução. Porém, são as ações realizadas pelo usuário na interface que favorecem o acompanhamento da sua evolução nos conceitos veiculados pela mesma. Por esse motivo, cabe uma avaliação dos resultados encontrados na literatura sobre o estilo de interação MD - Manipulação Direta - no tocante ao esforço cognitivo conseqüente do seu uso.

O termo Manipulação Direta [15], é utilizado para referenciar sistemas que representam na interface os objetos utilizados no momento. As ações na tela são realizadas através de botões, ou de manipulação do mouse, utilizando operações reversíveis, incrementais e rápidas cujo impacto no objeto utilizado seja imediatamente visível. Os benefícios da manipulação direta residem nas seguintes características: os usuários novatos podem aprender funcionalidades básicas rapidamente, geralmente mediante uma demonstração; os usuários experientes se tornam mais eficientes para uma grande quantidade de tarefas; as mensagens de erro são utilizadas raramente; os usuários podem ver imediatamente se suas ações os conduziram para seus objetivos; os usuários reduzem o nível de ansiedade porque o sistema é compreensível e porque as ações são facilmente reversíveis.

Embora a manipulação direta se apresente como um estilo de interação aceito pelo usuário, a literatura da área conclui que as características benéficas provenientes desse estilo resultam do fato de ele solicitar pouco esforço cognitivo e, dessa forma, exigir o mínimo de aprendizagem necessária. Uma alternativa apontada por Sedighian [17] é mudar o foco, ou seja, colocar o usuário para manipular diretamente os conceitos do domínio, possibilitando a interação e a formulação de pensamentos voltados mais para os conceitos que estão sendo aprendidos do que para os seus objetos representativos. Assim, o mesmo autor [17] diz que o foco deve ser deslocado da manipulação direta de objetos para a manipulação direta de conceitos.

Manipulação Direta de Objetos - MDO: Reduz a distância semântica entre os objetos da interface e o modelo mental do usuário. Ou seja, sabe como ele pensa e oferece algo parecido, o que exige pouco esforço cognitivo e possibilita uma adaptação mais rápida à interface.

Manipulação Direta de Conceitos - MDC: Nessa interação, o usuário é convidado a se adaptar gradualmente à semântica dos conceitos. Isto é, faz o indivíduo mudar aos poucos seu modelo mental e, conseqüentemente, o leva à aprendizagem. Em outras palavras, o usuário é conduzido a pensar sobre os conceitos que estão metaforicamente representados pelos artefatos da interface.

Manipulação Direta Reflexiva de Conceitos MRDC: É a MDC - Direct Concept Manipulation estendida com Scaffolding ou suporte interacional. Nesse modelo estudantes são submetidos a um esforço cognitivo maior do que quando utilizava o MDO e MDC. Esse estilo de interação é proveniente da extensão da MDC por meio do uso de um feedback, chamado Scaffolding, que é oferecido durante a interação.

\subsection{Tipos de Scaffolding}

O scaffolding se caracteriza pela progressiva diminuição da regulação realizada pelo tutor, a medida em que o aluno começa a captar o significado funcional das ações a serem realizadas. Nesse estudo são apresentados tipos de scaffolding adaptados ao desenvolvimento da interface de softwares educacionais.

Compartilhamento dos objetivos específicos: Um ponto central do Scaffolding bem sucedido é a noção da compreensão compartilhada do objetivo da atividade. Embora alguns elementos da atividade estejam além da compreensão do aprendiz, a intersubjetividade ou compreensão compartilhada da tarefa ajuda a fornecer a motivação para concluí-la. Dessa forma, percebemos que o compartilhamento de objetivos específicos possibilita a manutenção do interesse do aprendiz. Nesse caso, o objetivo específico do aplicativo é ensinar altimetria: temperatura local, temperatura padrão, pressão atmosférica, escalas de pressão e a fórmula para o ajuste da altitude.

Engajamento / Manutenção do interesse do aluno: Consiste em atrair a atenção do aluno para a realização da tarefa. Uma forma eficaz de aumentar o envolvimento dos alunos em uma tarefa é tornando a mesma atraente, de forma a aumentar a motivação dos alunos. A motivação nessa aplicação vai além 
da representação gráfica e está diretamente relacionada com a aplicação prática onde cada ação do aluno, resulta em um efeito diferente no cenário operacional.

Redução do grau de liberdade: Tem como objetivo permitir ao aprendiz desenvolver suas habilidades nos componentes da tarefa que ele pode controlar. A redução do grau de liberdade é obtida através da redução dos passos necessários para a realização da tarefa, restringindo as ações e o fornecimento de fedback por parte do tutor. Esse tipo de scaffolding pode ser observado na restrição operacional na primeira etapa de interação no aplicativo, nela só é permitido ao aluno a troca do cenário operacional e a manipulação do altímetro. Essa restrição tem como objetivo fazer o aluno perceber os níveis intermediários de conhecimento que conectam os níveis mais baixos e evidentes, sinalizados pela alteração no cenário/ambiente com o nível mais alto onde o conhecimento mais intrínseco e complexo está representado, no caso a altimetría.

Manutenção do sentido / direção: Tem como propósito impedir que o aprendiz se desvie do objetivo ou do caminho necessário para o cumprimento da tarefa. Durante o processo de realização da atividade é função do tutor manter a motivação do estudante voltada para aquilo que ele está realizando, para que o mesmo possa aprender os conceitos envolvidos na resolução da tarefa. No caso de simulações, esse tipo de scaffolding pode ser desenvolvido através da integração dos dois outros tipos citados anteriormente, oferecendo ao aluno a simulação aberta como forma de motivação, se contrapondo a obrigação de orientar o aluno direcionando a aprendizagem por meio de uma simulação fechada com restrição de passos e interações.

Simplificação da tarefa / Destaque de aspectos críticos: Consiste no destaque a ser dado pelo professor, durante o ensino de um conteúdo, às partes que ele julga relevantes tanto para o processo de aprendizagem quanto para a resolução de problemas. $\mathrm{O}$ uso dessas partes relevantes pelo aluno pode ser posteriormente utilizado pelo professor como critério para medir o progresso do aluno na aprendizagem e no domínio do conhecimento e habilidade necessários para o cumprimento da tarefa. Esse processo foi definido ainda juntamente com o compartilhamento dos objetivos específicos, tendo como meta, extrair as funcionalidades mais básicas a serem modeladas no aplicativo. Essa simplificação além de facilitar o processo de aprendizagem focando nas funcionalidades e conceitos principais a serem trabalhados, con- tribui para a agilização do processo de desenvolvimento do aplicativo.

Controle da frustração: A realização de uma tarefa pode tornar-se uma experiência estressante quando existem dúvidas por parte do aprendiz de como resolvê-la. Embora seja do professor a responsabilidade de procurar diminuir a frustração do aprendiz, aumentando sua motivação para o aprendizado, esse tipo de scaffolding em um aplicativo educacional incorpora conceitos de usabilidade no design da interface, através do fornecimento de feedbacks a cada ação do usuário. Esse feedback pode ser positivo ou negativo, informando o sucesso e confirmando assim assimilação do conhecimento ou o insucesso, exigindo a reflexão para a reformulação da estratégia na realização da tarefa.

Demonstração / Fornecimento de trajetos ideais da solução: Consiste em desenvolver modelos de soluções para a tarefa ou para partes dela, de forma a facilitar a percepção por parte do aluno dos conceitos e procedimentos relevantes na realização da atividade. As principais teorias construtivistas de aprendizagem apontam a construção do conhecimento através da constituição de caminhos alternativos a serem identificados pelo aluno baseado em referências de sucesso. Nesse aplicativo, são oferecidos modelos variacionais de sucesso relacionados a cada tipo de cenário, permitindo que através da percepção de padrões de resposta o aluno possa configurar o seu próprio modelo.

Foco na resolução da tarefa completa: Embora a tarefa possa ser dividida em subtarefas, a literatura sobre Scaffolding conclui que é melhor focar no problema como um todo, do que em suas subcategorias. Esse aspecto do Scaffoding significa que os aprendizes manterão sua atenção em adquirir habilidades para a tarefa completa, o que constitui o objetivo para o qual estão sendo treinados. Como citado anteriormente, em outros tipos de scaffoldings a divisão em subtarefas permite ao aluno observar que cada tarefa representa um agrupamento de ações, cujo objetivo específico é um fragmento do objetivo geral, resultante da completude da tarefa.

A disponibilidade imediata da ajuda: A idéia desse elemento é fornecer aos aprendizes uma ajuda imediata. Se não lhes for fornecido esse auxílio imediato, eles podem se frustrar com a tarefa e, assim, não conseguir seu objetivo. Esse scaffolding em aplicativos educacionais também é elaborado para manter o controle da frustração do aluno através de orientações pré-planejadas ou materiais explicativos complementares com conteúdo desenvolvido a partir das 
dificuldades percebidas e apontadas por alunos aos professores.

Ajudar quando houver necessidade: Similar à última idéia, esse elemento do Scaffolding incentiva o instrutor a ajudar, imediatamente, o aprendiz, tomando por base se a ajuda foi ou não necessária. Caso a ajuda seja fornecida em outro momento, haverá uma interrupção do pensamento do aprendiz. Assim, nesse modelo a ajuda pode ser oferecida não de forma direita (não seria direta?), mas através de referências com outras formas de apresentação do conteúdo, como infográficos, mapas conceituais.

Fornecimento de uma ajuda efetiva: A ajuda efetiva envolve disponibilidade imediata, porém apenas quando for necessário. Como essa ajuda deve oferecer parte da solução para o aluno, deve haver a apresentação dos conceitos propriamente ditos através de representações concretas.

Conhecimento do modelo do tutor: Um modelo do tutor dá aos aprendizes informações acerca das habilidades que precisam adquirir. Tendo uma representação ideal da habilidade que estão tentando adquirir, os aprendizes terão uma idéia do objetivo para os quais estão sendo treinados. Esse modelo do tutor foi integrado no aplicativo, onde o próprio computador fornece ao aluno modelos referenciais de comportamento de acordo com o cenário configurado pelo aluno.

Divisão de uma tarefa maior em suas subtarefas: O propósito da divisão de tarefas em subtarefas é o de facilitar o entendimento da tarefa maior por meio da sua subdivisão em tarefas menores. A tarefa de ajustar o altímetro foi divida em 3 subtarefas, sendo: ajustar a temperatura, ajustar a pressão atmosférica e, finalmente, ajustar a altitude. Essa divisão foi estabelecida com a finalidade de atender ao objetivo específico e permite ao aluno conectar os diferentes níveis específicos de conhecimento até atingir o nível mais abstrato.

Estruturação e Problematização: O scaffolding se torna necessário frente a uma tarefa que possui uma maior complexidade de natureza aberta ou não estruturada. A problematização surge como uma forma de impedir que os passos da tarefa sejam negligenciados. A estruturação é utilizada como uma forma de organizar o pensamento do estudante, fazendo-o refletir. Por exemplo, se os estudantes forem forçados a usar um menu para categorizar os dados coletados, ou no caso selecionar um cenário/aeroporto/localidade, eles terão que considerar seu significado, sendo obrigados a refletirem sobre tais categorias. Assim, a problematização sobre a- quele conteúdo ou a diferenciação entre sua forma de apresentação leva o aluno a questionar e refletir sobre a mudança percebida, revelando a estruturação e correlação entre os níveis de linguagem que o conhecimento está distribuído, o que torna o design de interação uma ferramenta tão importante para instigar e levar o aluno à reflexão, quanto à representação gráfica.

A criação de um software educativo de boa qualidade requer a observação de detalhes em cada etapa de desenvolvimento, pois trata da criação de um sistema dinâmico com especificações e requisitos específicos quanto à interação com o usuário e seu impacto sobre a aprendizagem. Face ao exposto, apenas a análise da tarefa é insuficiente, pois nesse contexto não apenas a tarefa é relevante mas, também, os aspectos cognitivos dos usuários.

Neste sentido a utilização de scaffolding em um software educacional requer a compreensão do papel a ser desempenhado pelo software enquanto parceiro do aluno no processo de aprendizado. As categorias de scaffolding vistas na seção anterior destacam questões importantes a serem atendidas no projeto desse recurso, que tem como objetivo final oferecer ajuda adequada às necessidades dos usuários.

Uma forma de adequar o scaffold utilizado em um software educacional às necessidades dos alunos é investigar o processo de execução da tarefa realizado pelos alunos. A partir da observação dos passos, procedimentos, observações e dificuldades apresentados pelos alunos durante a execução da tarefa é possível formular uma ajuda adequada ao aprendizado do conteúdo em questão. Outras fontes de inspiração a serem consideradas no projeto do scaffolding podem ser encontradas no próprio conteúdo a ser veiculado na interface, através da identificação dos conceitos e invariantes necessários a aprendizagem do assunto bem como na análise de programas concorrentes.

As metáforas, também são consideradas por Bruner [18] como mecanismos de sustentação (scaffolding) para o aprendizado, possibilitando que informação previamente aprendida torne-se aplicável a novas situações. O foco no uso de metáforas em interfaces evoluiu da motivação inicial como facilitadora do aprendizado para incluir a facilidade de uso. Conscientes de que o objetivo da metáfora na interface é prover o usuário com um modelo do sistema com o qual deverá interagir, Erickson [7] propõe o uso de metáforas em design através de um processo baseado nas seguintes etapas:

1) Entender a funcionalidade do sistema a ser cria- 
do;

2) Como nenhuma metáfora consegue modelar todos os aspectos da funcionalidade de um sistema, deve-se identificar as partes do conteúdo da disciplina que o aluno tem mais dificuldade de entender;

3) Metáforas que "suportem" o modelo requerido, devem ser geradas e avaliadas. Na geração de metáforas candidatas, notar metáforas já implícitas na descrição do problema e procurar eventos reais, objetos ou organizações que incorporem algumas das características que os alunos acham difícil entender. Das metáforas geradas, escolher uma através da qual será expressa a funcionalidade do sistema, com base nos aspectos de estrutura, sua aplicabilidade, poder de representação, adequação ao público alvo.

Em relação à estrutura, o objetivo é verificar quanto da estrutura de apoio a aprendizagem, a metáfora ajuda ao usuário pensar no conceito veiculado por ela. Em relação à aplicabilidade deve ser verificado se a metáfora é relevante ao problema; metáforas que podem conduzir o usuário na direção errada ou levantar falsas expectativas devem ser evitadas.

Quanto à representação, metáforas ideais têm representações visuais distintas e palavras específicas associadas. Em relação à adequação ao usuário, deve-se verificar se o público-alvo entende a metáfora; ela seria inútil em caso negativo.

Madsen [11], com base em estudos de casos realizados e coletados da literatura, propõe uma série de orientações para o design baseado em metáforas. $\mathrm{O}$ processo é composto por 3 diferentes atividades:

Fase (1) - geração de metáforas:

- Observar como os usuários entendem seus sistemas computacionais;

- Construir sobre metáforas já existentes;

- Usar artefatos predecessores como metáforas. Notar metáforas já implícitas na descrição do problema;

- Procurar eventos do mundo real que exibam aspectos chave.

Fase (2) - avaliação de metáforas candidatas ao design:

- Escolher uma metáfora com uma estrutura rica. Avaliar a aplicabilidade da estrutura;

- Escolher uma metáfora adequada ao perfil do usuário. Escolher metáforas com significado literal bem entendido;
- Escolher metáforas com uma distância conceitual entre a fonte e o significado metafórico;

- Ter pelo menos um conceito como "ponte" entre o significado literal e o metafórico;

- Não necessariamente incorporar a metáfora no design final.

Fase (3) - desenvolvimento do sistema propriamente dito:

- Elaborar o conceito principal;

- Procurar novos significados para o conceito;

- Reestruturar a nova percepção da realidade;

- Elaborar suposições tornando explícito o que a metáfora esconde e o que ela salienta;

- Contar a estória da metáfora, falando do domínio alvo como se ele fosse o domínio fonte;

- Identificar as partes não usadas da metáfora;

- Gerar situações de conflitos.

A partir da definição dos tipos de scaffolding, descritos anteriormente, podemos apontar os seguintes passos para a confecção de uma interface educacional baseada no uso de scaffolding:

\section{Estruturar Tarefas e Funcionalidades}

- Definir o cenário operacional e os conceitos a serem veiculados na interface;

- Identificar os conceitos necessários ao aprendizado deste cenário;

- Identificar as situações que tornam esses conceitos significativos e oferecer essas situações ao usuário;

- Definir as diferentes representações que serão utilizadas para lidar com essas situações e permitir ao usuário fazer uso delas durante o uso da interface;

- Definir a conexão entre algumas das representações utilizadas e de que forma o usuário poderá utilizar estas conexões para passar informações de uma representação para outra;

- Identificar os invariantes que devem ser capturados pelos usuários ao lidar com essas situações;

- Projetar o scaffolding (ajuda para o usuário) a ser utilizado na interface de forma a facilitar a percepção desses invariantes bem como auxiliar o usuário no processo de resolução de problemas com a interface;

- Restringir uma tarefa complexa por definição de "limites de coerência" para os alunos; 
- Viabilizar a visualização de tarefas complexas usando a decomposição ordenada e desordenada das tarefas;

- Restringir o espaço de atividades usando modos funcionais;

- Desenvolver um protótipo para realização de testes com usuários;

- Avaliar os invariantes mobilizados pelo usuário ao utilizar o protótipo bem como a eficácia do scaffolding em auxiliar o aluno durante o uso da interface educativa;

- Caso necessário, realizar modificações no protótipo e testar novamente com o usuário. Repetir o ciclo (modificação do protótipo/teste/avaliação) até que o software seja considerado adequado para a aprendizagem dos conceitos nele veiculados.

\section{Fornecer acesso ao conhecimento do especialista}

- Fornecer conteúdo de orientação para ajudar os alunos a participar de processos científicos

- Fornecer informações para o uso da ferramenta

- Fornecer informações metacognitivas.

Automatizar de forma implícita as tarefas de rotina

- Facilitar a organização dos elementos de interação

- Facilitar a circulação entre as ferramentas e as atividades

- Automatizar partes de tarefas para reduzir demandas cognitivas acima do esperado

Usar representações que podem ser identificadas pelos alunos

- Fornecer representações que podem ser identificadas pelos alunos que ajudem a revelar conceitos subjacentes

- Dar aos alunos a capacidade de ligar diferentes pontos de vista sobre o mesmo conteúdo

- Dar aos alunos "pontos de vista mutáveis" que lhes permitam manipular diretamente (ou alterar) as representações
Usar representações e linguagem como ponte para a aprendizagem

- Fornecer organizadores visuais conceituais para dar acesso uma funcionalidade

- Usar terminologia que forneça aos alunos conceitos intuitivos para descrever conceitos complexos

Facilitar a articulação de descrições e explicações

- Destacar as características epistêmicas das descrições para apoiar o desenvolvimento de descrições científicas

Facilitar a articulação das ações e do progresso da tarefa

- Dar aos alunos um espaço para facilitar o planejamento de aspectos do resultado de sua ação

- Fornecer informações e orientações para facilitar o monitoramento

\section{Desenvolvimento Ágil de OAs}

O modelo de Projeto Instrucional Dirigido pelo Comportamento descrito na seção 3 foi levado a efeito com a participação de instrutores, alunos e expertises. Sendo assim, para identificar os requisitos e funcionalidades que deveriam ser abordados no OA proposto, realizamos entrevistas semiestruturadas com instrutores e alunos do Instituto de Controle do Espaço Aéreo [9], em setembro de 2007, onde apuramos as dificuldades em se construir cognitivamente um modelo do momento em que os conceitos abstratos de Meteorologia influenciam significativamente nos procedimentos operacionais.

$\mathrm{Na}$ elaboração da proposta de atividades contamos com a colaboração de um controlador de tráfego aéreo com uma gama de conhecimentos, habilidades, convicções e conceitos adquiridos ao longo dos 20 anos de atividade profissional. Sua contribuição faz com que o workflow de produção de um objeto de aprendizagem dirigido a treinamentos para atuar em Sistemas Complexos pareça diferente de um OA 'simples', ao inserir a participação de expertises nos processos de identificação de cenários e produção de recursos educacionais. 


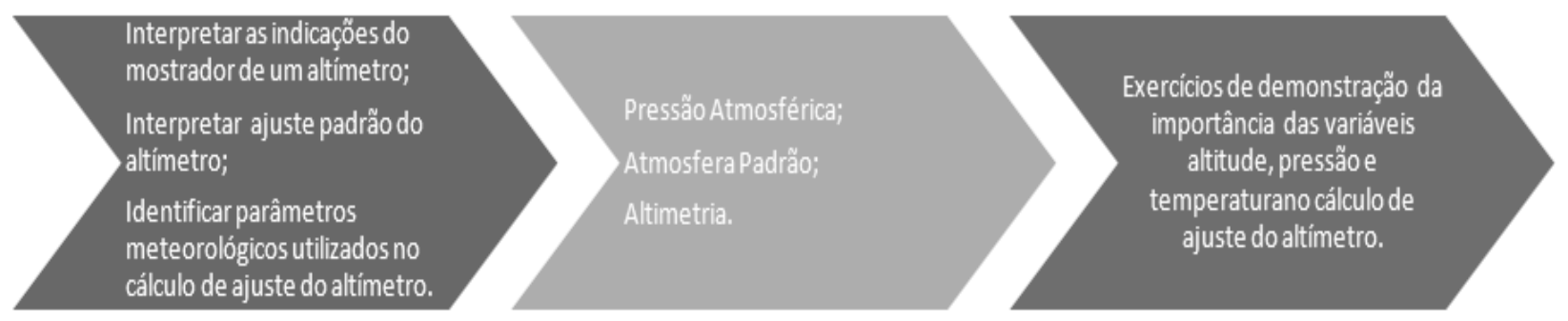

Figura 6 - Proposta de atividade do aplicativo

Vale ressaltar que um mesmo conteúdo pode admitir mais que uma atividade de aprendizagem assim como uma mesma atividade de aprendizagem ser utilizada para alcançar diferentes objetivos previstos pelos grupos disciplinares. A identificação do cenário (contexto) foi obtida por meio de entrevistas semi-estruturadas, em que foram identificados os momentos em que os conceitos relacionados à pressão atmosférica, atmosfera padrão e altimetria influenciam significativamente nos procedimentos operacionais. Desse modo, a idéia principal do objeto de aprendizagem é possibilitar a revisão dos conceitos relacionados à pressão atmosférica, atmosfera padrão e altimetria por meio de exercícios práticos que estimulem sua compreensão e fixação.

Dentro do modelo instrucional proposto de desenvolvimento de OA, a metodologia que se mostrou mais eficiente para atender as demandas variacionais de modelagem das funcionalidades do aplicativo foi a metodologia ágil de Extreme Programming (XP). Essa metodologia ágil permite desenvolver aplicativos com requisitos vagos, imprecisos ou em constante mudança, através da estratégia de constante acompanhamento e realização de vários pequenos ajustes ao longo do desenvolvimento. Esta abordagem segundo Yeomans apud. Boyle [4] salientam:

- Prototipagem rápida e iterativa;

- Uso de pequenas equipes ágeis;

- Usuário na equipe de projeto;

- Ênfase em produtos em vez de seguir processos definidos;

- Prazos apertados, embora controlados por métodos de gestão do tempo.

Os quatro valores fundamentais da metodologia XP são: comunicação, simplicidade, feedback e coragem. A partir desses valores, possui como princípios básicos: feedback rápido, presumir simplicidade, mudanças incrementais, flexibilidade frente a mudanças e trabalho de qualidade. Dentre as variáveis de controle em projetos (custo, tempo, qualidade e escopo), há um foco explícito em escopo. Para 28 alcançar controle, recomenda-se a priorização de funcionalidades que representem maior valor possível para o negócio. Desta forma, caso seja necessário a diminuição de escopo, as funcionalidades menos valiosas serão adiadas ou canceladas. O desenvolvimento do OA foi apoiado, nas boas práticas da metodologia XP que é definido por Beck [2,3] e adaptada a todas as áreas envolvidas no processo como descrita a seguir:

Jogo de Planejamento (Planning Game): Nesse modelo, há uma interação muito próxima entre cliente e desenvolvedor. Aos programadores cabe a estimativa do esforço necessário para a execução das histórias do cliente, enquanto ao cliente cabe a decisão sobre o escopo e o prazo de desenvolvimento das versões para acompanhamento do andamento do projeto. No desenvolvimento de objetos de aprendizagem os clientes poderiam ser instrutores, especialistas, professores ou o designer instrucional, pois determinariam as funcionalidades e prioridades a partir de um modelo pedagógico e da experiência prática em sala de aula.

Metáfora (Metaphor): Todo o sistema é definido por um conjunto de metáforas entre o cliente e os programadores, através de um sistema de códigos de linguagem. $\mathrm{O}$ estabelecimento desse código visa facilitar a comunicação com o cliente traduzindo o conjunto de funcionalidades em uma linguagem próxima a realidade dele. Nesse caso, o sistema de códigos foi construído tendo como referencial a realidade do aluno, identificada pelo professor ou pelo designer instrucional.

Equipe Coesa (Whole Team): No projeto recomenda-se a composição de equipes não muito numerosas com um representante de cada área de desenvolvimento. Fizeram parte da equipe, o cliente, o programador, o designer e o designer instrucional que estiveram em sintonia com professor onde a coesão permitiu uma melhor integração das partes de desenvolvimento.

Projeto Simples (Simple Design): A ênfase está em projetar a solução mais simples possível e exequiível 
neste momento. Complexidade desnecessária e códigos extras são removidos imediatamente, buscando implementar as funcionalidades essenciais para o cumprimento da proposta pedagógica.

Programação em Pares (Pair Programming): A programação é realizada em par/dupla num único computador com o aplicativo sendo revisto por duas pessoas, evitando e diminuindo assim a possibilidade de erros. Esse mesmo modelo foi adotado em outras partes de desenvolvimento do aplicativo, como no design.

Padrões de Codificação (Coding Standards): São estabelecidos códigos padronizados pela equipe de desenvolvimento a fim de integrar e facilitar o processo de construção do aplicativo. No caso do objeto de aprendizagem, a codificação foi pautada na linguagem técnica da área.

Posse Coletiva (Collective Ownership): O códigofonte é compartilhado entre os desenvolvedores podendo ser modificado ao mesmo tempo e construído de forma colaborativa. O objetivo com isto é fazer a equipe conhecer todas as partes do sistema podendo ser feita a atualização do desenvolvimento através de repositórios de versões compartilhado pela equipe.

Refatoração (Refactoring): Definição e redefinição da arquitetura a todo o momento em um aperfeiçoamento contínuo do projeto, após a consolidação de uma funcionalidade, com o mínimo de introdução de erros e mantendo a compatibilidade com o código já existente. No caso da programação, refatorar melhora a clareza (leitura) do código, dividindo-o em módulos mais coesos e de maior reaproveitamento, evitando a duplicação de código-fonte. Nas áreas de programação e design, a refatoração foi constante, de maneira integrada, com o aperfeiçoamento do código e do designer de forma progressiva, simultânea e complementar.
Reuniões em Pé (Stand-up Meeting): Realização de reuniões de curta duração entre os membros da equipe para discutir tarefas realizadas e tarefas a serem realizadas pela equipe. Esse formato é utilizado com o objetivo de conseguir maior concentração dos membros durante a reunião. Esse modelo foi adaptado em alguns momentos, com o uso de ferramentas de comunicação síncrona, no caso o Skype, devido à impossibilidade de deslocamento do cliente.

Integração Contínua (Continuous Integration): A integração de novas funcionalidades é realizada de maneira contínua e imediata evitando a possibilidade de conflitos e erros no código fonte, permitindo acompanhar o status real da programação pelo cliente, facilitando a identificação de ajustes a serem realizados nas funcionalidades do aplicativo. No desenvolvimento do OA, houve a integração contínua de novas funcionalidades não só na programação, como também no design, a fim atender a proposta pedagógica.

Pequenas Versões (Small Releases): O desenvolvimento modulado do aplicativo permitiu a liberação de pequenas versões com partes essenciais para a utilização e testagem simultaneamente da seqüência de desenvolvimento e aperfeiçoamento do aplicativo. Esse processo permitiu o acompanhamento pelo cliente, orientando os ajustes a serem realizados.

Testes de Aceitação (Customer Tests): Testes unitários realizados antes do desenvolvimento final do código são executados de forma contínua ao longo do projeto, sendo os clientes responsáveis por especificar os testes funcionais através da relação de requisitos de funcionamento do objeto de aprendizagem. 


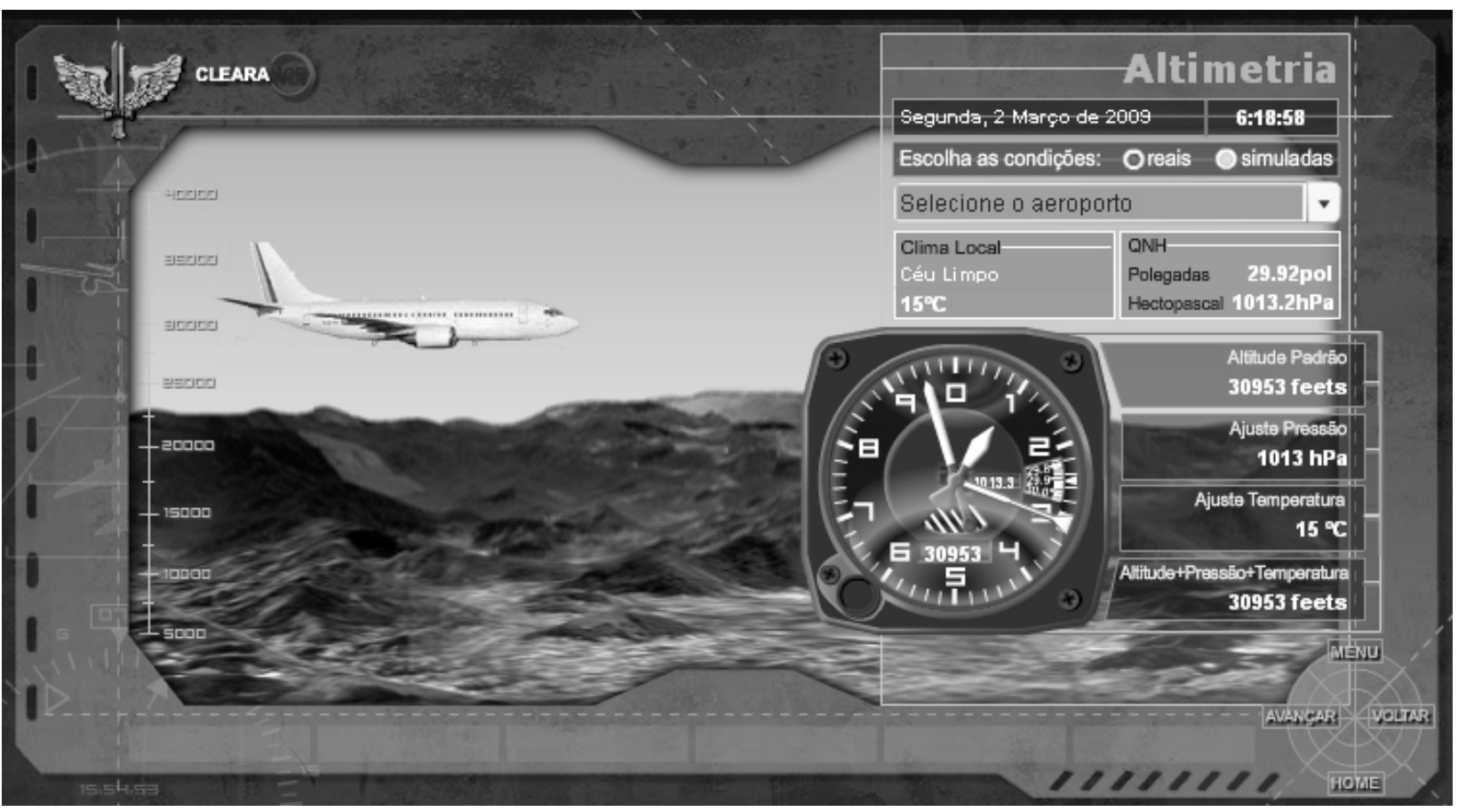

Figura 7 - Objeto de aprendizagem para trabalhar conceitos de altimetria

O modelo de desenvolvimento proposto e seguido, resultou no Objeto de Aprendizado chamado ClearaNCE (Figura 7) que trabalha os conceitos de altimetria que envolvem variáveis climáticas no ajuste da altitude voada por uma aeronave. Essas variáveis são: temperatura e pressão atmosférica aferidas localmente em cada aeroporto do país. O aplicativo foi desenvolvido em Flash junto com a linguagem de programação Action Script, integrada a busca e captura de dados em linguagem XML diretamente da Rede de Meteorologia do Comando da Aeronáutica (REDMET), dados esses referentes às condições meteorológicas do aeroporto escolhido. Nele, o aluno é estimulado a descobrir qual a relação entre temperatura local e a altitude da aeronave observando a modificação do cenário de acordo com as condições climáticas usadas para representar a temperatura. O conhecimento sobre pressão atmosférica está relacionado à temperatura através da escala barométrica sendo a escala mais baixa referente à temperatura mais baixa (e vice-versa). Através desta escala, o aluno é orientado a fazer o ajuste do altímetro. Esse ajuste também é feito a partir dos dados numéricos capturados. Nesta etapa, ocorrendo à variabilidade da temperatura e da pressão atmosférica de acordo com a localidade escolhida há a necessidade de ajuste do altímetro, o que estimula o aluno a descobrir essa correlação entre as variáveis.

\section{Avaliação}

A análise do processo foi realizada através de estudo de caso com instrutores de controle de tráfego aéreo com mais de 20 anos de experiência. A partir dessa prática analisamos a relação experimentação - objeto de aprendizagem para verificar se a estrutura aplicada no ClearaNCE proporcionaria uma boa receptividade e percepção da aplicação prática do conteúdo dentro de uma proposta diferenciada, verificando se a metodologia utilizada possibilitaria ou não a ação investigativa e reflexiva do aluno sobre os conceitos abordados.

Os participantes reforçaram que o OA conseguiu representar a aplicação dos conceitos de maneira correta e completa, facilitando o entendimento do procedimento operacional, ao dar uma noção concreta da importância destes Fundamentos da Meteorologia. Para eles, a apresentação de conceitos conjugados facilitam a generalização e contextualização da aplicação concreta do conceito, levando o aluno a conscientização de sua importância e a tomada de decisões mais conscientes. De modo geral, eles julgam que a inclusão de recursos como o ClearaNCE em cursos de formação para atuar em sistemas complexos é de suma importância, uma vez que apóiam a compreensão de procedimentos em que há combinação de diferentes variáveis através representações que auxiliariam na eliminação ou redução de lacunas 
que poderiam levar à dificuldades durante realização do estágio prático.

\section{Considerações Finais}

O modelo apresentado foi baseado nos pressupostos das metodologias ágeis de desenvolvimento, mais especificamente o desenvolvimento dirigido pelo comportamento esperado do sistema. Ele é aplicável nas 3 importantes fases do planejamento, quais sejam: projeção de finalidades (objetivos), formas de mediação (construção de recursos) e metodologia de desenvolvimento. A finalidade da aplicação dos modelos de captura da história do usuário é estimular a participação dos expertises e futuros usuários do sistema durante o desenvolvimento do software. No âmbito educacional, o que se pretende com tal prática é aumentar o número de cenários que possam contribuir com a formação profissional, possibilitando ao aluno interiorizar o conhecimento de tal forma que seja possível a sua abstração e aplicação em diferentes situações, inclusive, as não previstas durante o seu treinamento. Assim, cabe a equipe de treinamento e desenvolvimento motivar a participação das partes envolvidas e interessadas na formação de futuros profissionais, mostrando a importância das práticas de desenvolvimento ágil para a definição de objetivos e construção de recursos didáticos, podendo ser expandido as outras etapas do modelode de modo que a preparação, a implementação, a avaliação, e a revisão da instrução seja visto como um processo integrado.

\section{Referências}

[1] Astels D., (2003) Test-Driven Development: A Practical Guide; Prentice-Hall PTR.

[2] Beck K.., (2003) Test-Driven Development: By Example; Addison-Wesley. Wesley.

[4] Boyle T., Cook, J.; Windle, R.; Wharrad, H.; Jeeder, D.; Alton, Rob.. An Agile method for developing learning objects. Proceedings of the 23rd annual ascilite conference: Who's learning? Whose technology? Sydney, Australia, 2006

[5] Churchville D., (2006), Disponível em : http://www.extremeplanner.com/blog (acessado em 10/06/2009).
[6] Cohn M., (2004) User Stories Applied: For Agile Software Development. Addison Wesley Longman Publishing Co., Inc., Redwood City, CA, USA.

[7] Erickson, T.D. (1990) Working with Interface Metaphors. Em B. K. Laurel (ed) The Art of Human-Computer Interface Design. Reading: Addison-Wesley Publishing Company.

[8] Hutchins E. L., J. D. Hollan, and Norman. Direct manipulation interfaces. HumanComput. Interact. 1985.

[9] ICEA - Comando da Aeronáutica Instituto de Controle do Espaço Aéreo, "Apostila de Treinamento dos Controladores de Vôo”.

[10] Lapolli F., Cruz C., Motta, C. L., Tolla, C, E., (2009) Modelo de Objetos de Aprendizagem Baseado em Metodologias Ágeis - Anais do XX Simpósio Brasileiro de Informática na Educação.

[11] Madsen, K.H. (1994) A Guide to Metaphorical Design. Communications of the ACM vol.37, n.12, pp. 57-62.

[12] North D., (2007) Introducing: Behaviourdriven development, Disponível em: http://dannorth.net/introducing-bdd/ (acessado em 3/06/2009).

[13] _._. (2007) Whats in a Story, Disponível em: http://dannorth.net/whats-in-astory/ (acessado em 3/06/2009).

[14] Puntambekar S., and R. Hübscher. (2005) Tools for scaffolding students in a complex environment: What have we gained and what have we missed? Educational Psychologist. 2005.

[15] Quintana C., J. B. Reiser, E. A Davis, J. Krajcik, R. Golan, E. Kyza, D. Edelson, and E. Soloway. (2002) Evolving a Scaffolding Design Framework for Designing Educational Software. Keeping Learning Complex: The Proceedings of the Fifth International Conference of the Learning Sciences. (ICLS). Mahwah, NJ: Erlbaum.

[16] Sedig K., M. Klawe, and M. Westrom. (2001) Role of interface manipulation style and scaffolding on cognition and concept learning in learnware. ACM Transactions on Computer-Human Interaction. 
[17] Sedighian K., M. Westrom.(1997) Direct Object Manipulation vs. Direct Concept Manipulation: Effect of Interface Style on Reflection and Domain Learning. Proceedings of the Twelfth Conference of the British Computer Society Human Computer Interaction Specialist Group - People and Computers XII. Bristol, England.

[18] Wood D. J., J. S. Bruner, and G. Ross. (1976) The role of tutoring in problem solving. Journal of Child Psychology and Psychiatry. 